\title{
VULNERABILIDADE SOCIAMBIENTAL EM DECORRÊNCIA DE ENCHENTES DO RIO ITAPECURU NO MUNICÍPIO DE CANTANHEDE, MARANHÃO
}

\author{
Igor de Luccas Santos(a), Ulisses Denache Vieira Souza ${ }^{(b)}$, Antonio Cordeiro Feitosa $^{(c)}$
}

(a) Núcleo de Estudos e Pesquisas Ambientais - NEPA, UFMA, igordeluccas23@gmail.com

(b) Núcleo de Estudos e Pesquisas Ambientais - NEPA, UFMA, ulissesdenache@hotmail.com

(c) Núcleo de Estudos e Pesquisas Ambientais - NEPA, UFMA, acfeitos@gmail.com

\section{Eixo: GEOGRAFIA FÍSICA E DESASTRES NATURAIS}

\begin{abstract}
Resumo
A ocupação do espaço às margens dos leitos fluviais constitui fator de vulnerabilidade de populações rurais e urbanas submetidas a diferentes níveis de vulnerabilidade socioambiental, situação recorrente nos grandes rios do Norte e Nordeste do Brasil. Nesse estudo, abordam-se os impactos das enchentes para evidenciar a vulnerabilidade socioambiental das famílias residentes nas áreas marginais ao rio Itapecuru no Município de Cantanhede, estado do Maranhão, em especial no ano de 2009, para localizar os povoados atingidos e demonstrar a situação de risco das ocupações irregulares.
\end{abstract}

Palavras chave: Vulnerabilidade socioambiental; Enchentes; Rio Itapecuru; Cantanhede-MA.

\section{Introdução}

Os estudos ambientais permitem uma abordagem sistêmica das bacias hidrográficas, o conhecimento e a avaliação de variados componentes, interações e processos ambientais, como as inundações por grandes enchentes de rios, que são fenômenos naturais recorrentes nos anos mais chuvosos. No entanto, quando o leito maior de um rio apresenta ocupação humana, a população fica vulnerável ao que consideramos de um desastre natural causado por enchentes quando há danos materiais e humanos.

A bacia do rio Itapecuru ocupa uma área correspondente $16 \%$ do território estadual, $52.972 \mathrm{~km}^{2}$, e seu rio principal, o Itapecuru, é um dos maiores rios genuinamente maranhense (UEMA, 2002). Muito importante para o estado, inclusive servindo para abastecimento de uma parte da capital do estado, São Luís, pelo sistema Italuís. A importância deste rio, para os municípios localizados na área de influência da bacia do Itapecuru, é desde o período Colonial, cuja vasta estensão do rio, continente adentro (cerca de $1.050 \mathrm{~km}$ ), favoreceu o processo de ocupação do interior do território maranhense (FEITOSA; ALMEIDA, 2002).

De acordo com o relatório de ações da Coordenadoria de Proteção e Defesa Civil do Estado do Maranhão (CEDEC-MA, 2014), em 2009, 140 municípios maranhenses decretaram estado de emergência por motivo 


\section{OS DESAFIOS DA GEOGRAFIA FÍSICA NA FRONTEIRA DO CONHECIMENTO \\ Instituto de Geociências - Unicamp \\ Campinas - SP \\ 28 de Junho à 02 de Julho de 2017}

de enchente, com 70.381 dasabrigados e 141.531 desalojados. Nove municípios integravam a bacia do rio Itapecuru, dentre os quais o de Cantanhede.

Neste trabalho abordam-se as condições de vulnerabilidade socioambiental a que se expôem parte dos moradores residentes nas proximidades do leito do rio Itapecuru, ao ocuparem parte da área do leito maior do Itapecuru, sujeitos as enchentes recorrentes no leito e margens do referido rio. Cantanhede tem suas terras drenadas pelo rio Itapecuru e alguns de seus afluentes, sendo afetado por enchentes de grande magnitude, em especial a ocorrida no ano de 2009.

Com o presente estudo, espera-se contribuir para o melhor conhecimento dos riscos a que se submetem as populações em estado de vulnerabilidade socioambiental que ocupam áreas do leito maior do rio Itapecuru, tanto em áreas urbanas como rurais de município de Cantanhede, identificando os povoados atingidos e os principais condicionantes que contribuem mais diretamente para os impactos, de modo a subsidiar ações de planejamento e para a gestão eficiente dos processos estudados.

\section{Métodos}

O desenvolvimento da pesquisa tem como fundamentação o metódo dedutivo (LAKATOS; MARCONI, 2003), procedendo-se o estudo do fenômeno das enchentes para subsidiar as observações e reflexões, além da sistematização dos acontecimentos mais recorrentes na área de estudo.

No desenvolvimento da pesquisa foram utilizados os seguintes procedimentos metodológicos: levantamentos bibliográficos acerca da temática ambiental e vulnerabilidade socioambiental, notícias de jornais, além de informações sobre o rio Itapecuru, e sobre o município de Cantanhede, que é utilizado como recorte espacial. Foi utilizada a representação cartográfica para representar a posição e situação dos povoados atingidos, e facilitar a vizualização da altitude das áreas afetadas.

\section{Localização da área de estudo}

O Município de Cantanhede está localizado na mesoregião Norte Maranhense e microrregião de Itapecuru Mirim, entre as coordenadas $03^{\circ} 31^{\prime} 56^{\prime \prime}$ e $03^{\circ} 46^{\prime} 13^{\prime \prime}$ de latidude sul e $44^{\circ} 01^{\prime} 48^{\prime \prime}$ e $44^{\circ} 27^{\prime} 31^{\prime \prime}$ de longitude oeste (Figura 1). O município está localizado no baixo curso do rio Itapecuru, esse trecho corresponde a $360 \mathrm{~km}$, desde Caxias até a foz rio Itapecuru, na Baia do Arraial, e o desnível total ao longe do referido trecho é de aproximadamente 50 m (MEDEIROS, 2001, apud SILVA; CONCEIÇÃO, 2011). Em Cantanhede, o rio Itapecuru possui quatro afluentes, o rio Peritoró, pela margem esquerda, e o riachos Cachimbo, Pitomba e Curimatá, pela margem direita (NUGEO, 2009). 


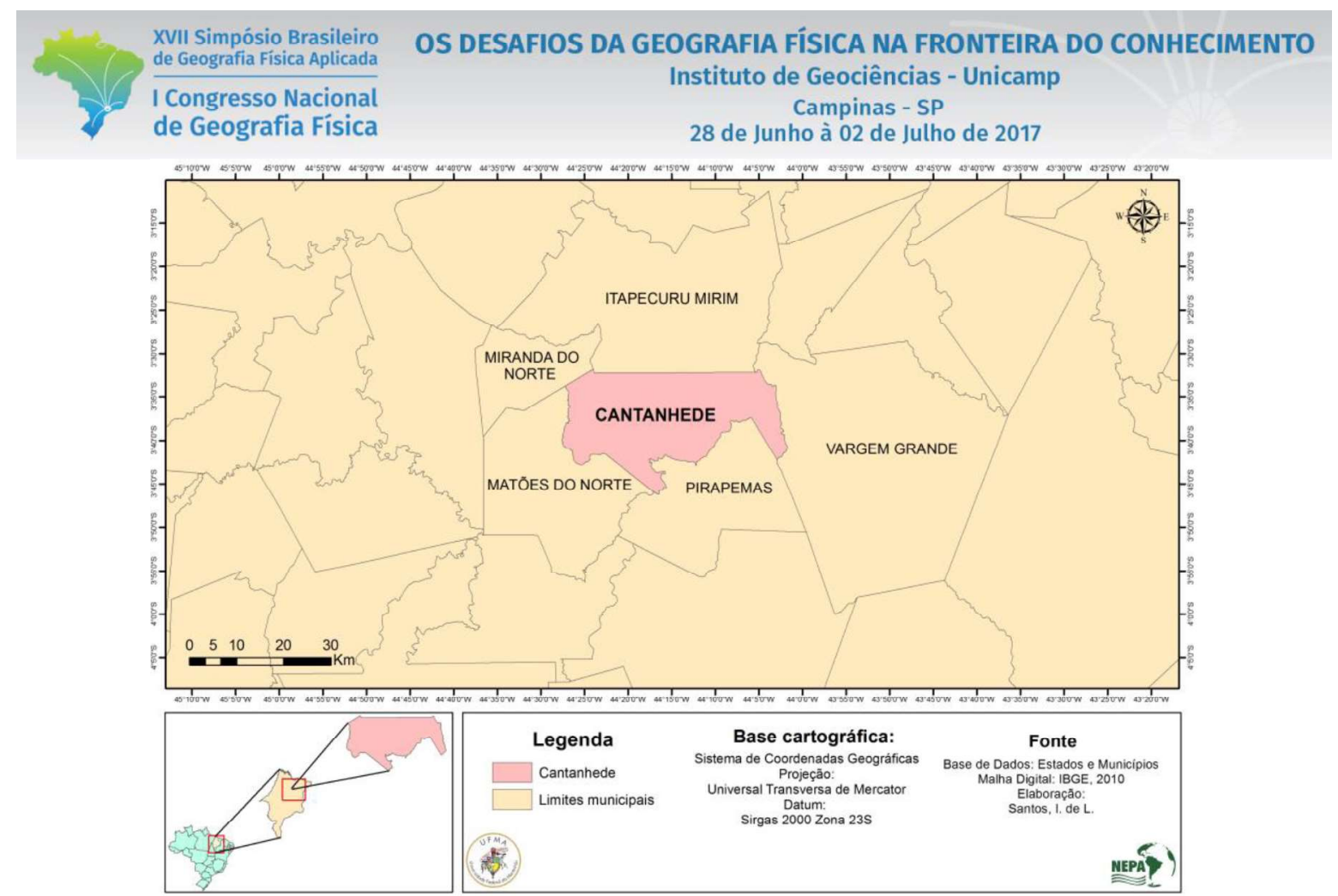

Figura 1 - Localização da área de estudo. Fonte: Adaptado do IBGE, 2010.

\section{Resultados e Discussões}

O termo enchente, segundo Tucci (2003, p. 26) consiste na "elevação do nível de água de um rio, acima de sua capacidade natural de escoamento, em perído de alta precipitação pluviométrica", já a inundação, conforme o mesmo autor ocorre quando as águas dos rios, riachos ou galerias pluviais transbordam o leito normal de escoamento em virtude da falta de capacidade de transporte de um destes sistemas e ocupa áreas onde a população utiliza para moradia, transporte, comércio, entre outros. Em Cantanhede o histórico de grandes enchentes do rio Itapecuru e seus afluentes ocorrem com grande intervalo temporal, como registrado nos anos de 1924, 1934, 1974 e 1986 (RABELO; LOUZEIRO; SOUZA; FEITOSA, 2012).

As médias pluviométricas no Estado do Maranhão, para os meses de março, abril e maio de 2009, foram, respectivamente, 419,79; 510,27 e 429,94 mm (CEDEC-MA, 2014), e os dados de precipitação mais próximos são da estação A220 da cidade de Bacabal, localizada a aproximadamente $100 \mathrm{~km}$ de Cantanhede, através do INMET - Instituto Nacional de Meteorologia, em 2009, os meses mais chuvosos na região foram março, abril e maio, com 349; 475 e 463 mm reespectivamente. A CEDEC-MA (2014) classificou a situação de Cantanhede, em 2009, como inundação gradual (enchente), entendida pelo orgão como "acréscimo das precipitações hídricas e com as inundações, ou seja, são caracterizadas pela elevação 


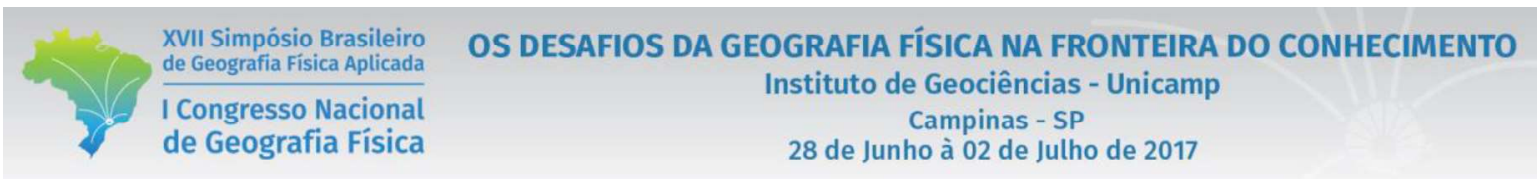

das águas de forma paulatina e previsível, mantendo-se em situação de cheia durante algum tempo, para após, escoarem-se gradualmente".

As enchentes como desastres naturais também foram pautas na mídia, em abril de 2009 o Jornal Pequeno divulgou que 500 pessoas em Cantanhade estavam desabrigadas e sem fornecimento de água, uma vez que a estação de captação foi destruída. Em maio do mesmo ano, o Jornal Pequeno trouxe informações que o nível do rio Itapecuru, em Cantanhede, estava 15m acima do nível normal (Figuras 2 e 3), e mais de 300 famílias já haviam sido retiradas dos povoados e levadas para abrigos. Estes fatos demonstram a vulnerabilidade, defendida aqui como, segundo Santos e Caldeyro (2007), uma comunidade, paisagem que se enquadra na condição de suscetível ao impacto de um evento.

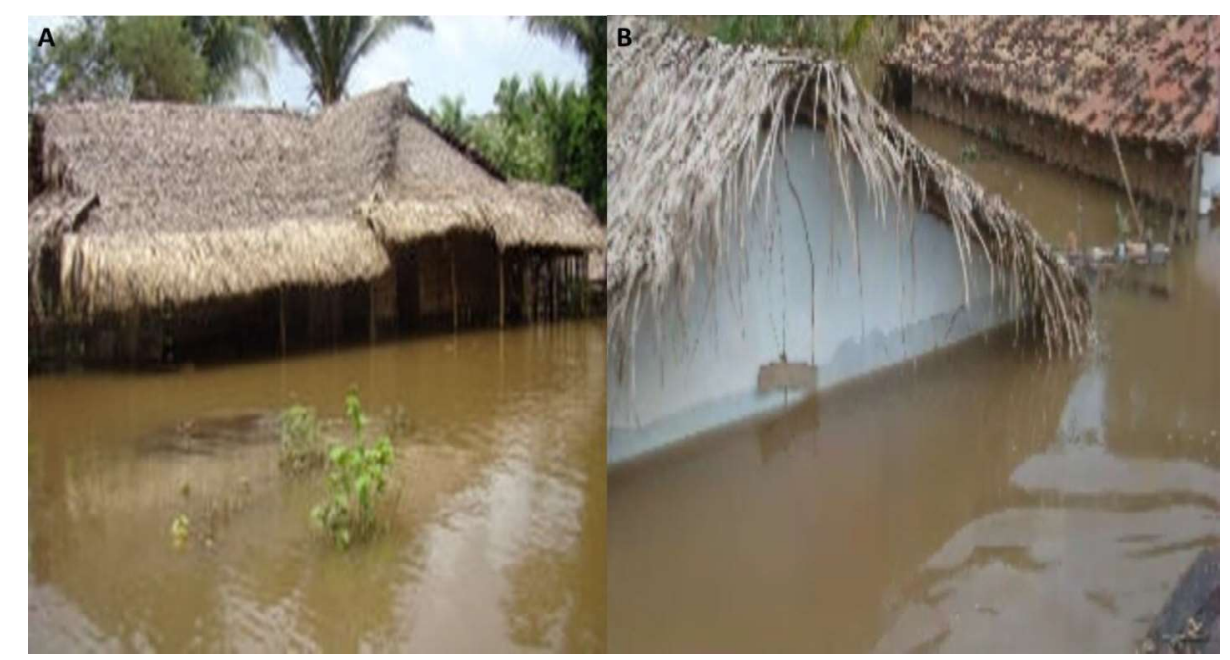

Figura 2 - Consequências da enchente de 2009 em Cantanhede: A e B - Casas tomadas pela água. Fonte - A - Jornal Pequeno, 2009; B - Proartepropaganda, 2009.

Embora não tenhamos acesso a um relatório específico para este caso que abranja todo o município, pelo banco de dados fornecido pela prefeitura de Cantanhede foi possível constatar que a maioria dos povoados atingidos ocupam áreas próximas ao leito do rio principal, e na margem direita, que é a área topograficamente mais baixa, são eles: Vila Nova; Trizidela; Galvão; Fumaça; Primavera; Pitomba I; Pitomba II; Candiba; São Domingos e Fumaça, e na margem esquerda: Garafinha, Cachimbos, Cachoeiras, Santa Luzia e a sede municipal (Figura 2).

\section{Considerações Finais}

Atualmente na área de estudo, além dos impactos da ocupação das terras do leito maior do rio Itapecuru, as práticas agrícolas e pecuárias também são uma ameaça à degradação das margens do rio Itapecuru e seus afluentes, pela destruição das matas ciliares. Uma vez retirada essa proteção vegetacional, as margens 


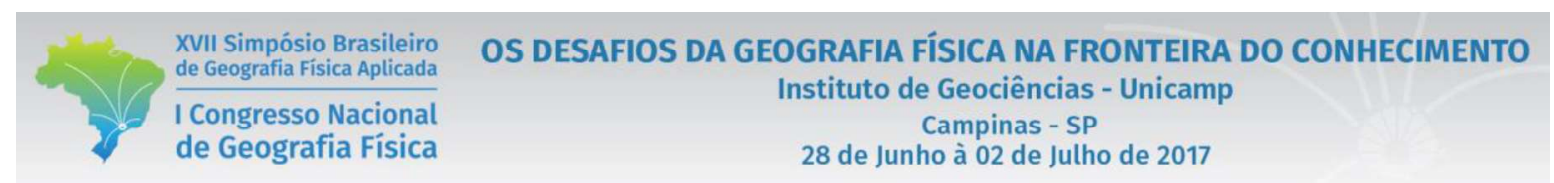

dos corpos hídricos ficam suscetíveis aos processos erosivos, dificultando a percolação das águas pluviais e favorecendo o escoamento superficial.

$\mathrm{O}$ assoreamento, somado às baixas cotas altimétricas dessa região, à alta pluviosidade, e à presença de afluentes favorecem as enchentes, e as cheias históricas deste rio evidenciam a situação de vulnerabililidade socioambiental da população ribeirinha, mas, embora haja um histórico de grandes enchentes no município, ainda ocorre ocupação nas áreas afetadas, portanto, com intuito de evitar perdas e danos materiais e humanos, o sensoriamento remoto nesse caso pode ser usado como ferramenta para delimitar as áreas afetadas pelas inundações auxiliando no ordenamento territorial do município e gestão do uso e ocupação das terrras, a fim de evitar futuras ocupações em locais que coloquem a população em situação de vulnerabilidade.

\section{Bibliografia}

CEDEC-MA - COORDENADORIA ESTADUAL DE PROTEÇÃO E DEFESA CIVIL DO ESTADO DO MARANHÃO. Relatório de Ações da CEDECMA “ANO 2009”. São Luís: CEPDECMA, 2014.

FEITOSA, A. C.; ALMEIDA, E. P. de. A Degradação Ambiental do Rio Itapecuru na Sede do Município de Codó - MA. São Luís: Caderno Pesquisa, n. 13, n 1, p 31-45, jan./jun., 2002.

Jornal Pequeno. Cheia do Itapecuru deixa desabrigados em Cantanhede. Publicado no dia 26 de março de 2009. Disponível em: <https://jornalpequeno.com.br/2009/04/26/cheia-do-itapecuru-deixa-desabrigados-em-cantanhede/>. Acesso em 15 de março de 2017.

FERREIRA, V. Cantanhede também sofre com enchente do rio Itapecuru. Jornal Pequeno. Publicado no dia 05 de maio de 2009. Disponível em: < https://edicao.jornalpequeno.com.br/impresso/2009/05/05/cantanhede-tambemsofre-com-a-enchente-do-rio-itapecuru/>. Acesso em 15 de março de 2017.

LAKATOS, E. M.; MARCONI, M. de A. Fundamentos da Metodologia Cientifica. $5^{\text {a }}$ ed. São Paulo: Atlas S. A. 2003.

NUGEO - Núcleo Geoambiental. Regiões Hidrográficas do Maranhão. UEMA/NUGEO, 2009. Disponível em < http://www.nugeo.uema.br/?page_id=233>. Acesso em 13 de março de 2017.

SANTOS, R. F. dos; CALDEYRO, V. S. Paisagens, Condicionantes e Mudanças. Cap. 2. In: SANTOS, R. F. dos (org). Vulnerabilidade Ambiental. Brasília: MMA, 2007.

SILVA, D. de J.; CONCEIÇÃO, G. M. da. Rio Itapecuru: caracterização geoambiental e socioambiental, município de Caxias, Maranhão, Brasil. Scentia Plena. Volume 7, nº 01, 2011.

DOI - 10.20396/sbgfa.v1i2017.2353 - ISBN 978-85-85369-16-3 
TUCCI, C. E. M. Inundações e Drenaem Urbana. In: TUCCI, C. E. M.; BERTONI, Juan C. Inundações Urbanas na América do Sul. Porto Alegre: ABRH, 2003.

UEMA. Atlas do Maranhão. São Luís: GEPLAN, 2002

RABELO, T. O.; LOUZEIRO, A. S.; DENACHE, U. D. V.; FEITOSA, A. C. Catástrofes Naturais no Maranhão: as principais cidades afetadas pelas enchentes do rio Itapecuru. In: $9^{\circ}$ SIMPÓSIO NACIONAL DE GEOMORFOLOGIA, 2012, Rio de Janeiro. Anais do $9^{\circ}$ SINAGEO (online), 2012. 